\title{
Analysis on the Factors of Satisfaction for Xinjiang Reconstruction-Assistance of Residents
}

\author{
Based on Ordinal Logistic Model
}

\author{
Aosiman Yusan \\ College of Economics and Trade \\ Urumqi vocational university \\ Urumchi, China 830002
}

\author{
Xehelaiti Mahemuti \\ School of Statistics and Information \\ Xinjiang University of Finance and Economics \\ Urumchi, China 830012
}

\begin{abstract}
This thesis takes the counterpart Xinjiang reconstruction-assistance project in recent five years as the main background, takes the satisfaction for Xinjiang reconstruction-assistance effects as the main investigation objective and takes the three districts in south Xinjiang with large intensity as the main investigation areas. Through the measure of questionnaire survey, conduct analysis on the satisfaction for the effects of implementation of Xinjiang reconstruction-assistance project of groups with different features by using the LOGISTIC model. It is found in the study that significant differences on the satisfaction for the effects of implementation of Xinjiang reconstruction-assistance project are displayed in aspects such as the natures of employment units of residents, industrial space layout and cultural degrees, etc. while there is no significant difference being displayed in the factors such as sex, nationalities and living space, etc. it is considered in this thesis that there are certain objective basis for the occurrence of above differences. After the implementation of Xinjiang reconstruction-assistance project, the feelings and attitudes toward Xinjiang reconstruction-assistance of different industries, different professions and different positions and between rural and urban crowds are different. If this situation continues, there will be new social alienation phenomenon which is not favorable to the accord development of Xinjiang economy, social stability and prolonged political stability and will cause that the economic objectives in Xinjiang construction cannot reach the expected effects. Corresponding political suggestions are put forward in this thesis.
\end{abstract}

Keywords-satisfaction for Xinjiang reconstructionassistance policy; factors; ordinal logistic model; residents

\section{INTRODUCTION}

After launching the first meeting on Xinjiang work in 2010, the central government put forward the counterpart Xinjiang reconstruction-assistance of nineteen provinces and cities, emphasized on accelerating the Xinjiang reconstruction-assistance from four aspects including cadres, talents, education and capital and promotion of industrialization degree of Xinjiang so as to lay the solid foundation for the rapid development of Xinjiang economy. Realize the self-development of Xinjiang and provide talents support by taking education assistance for Xinjiang as emphasis through development of human resource of
Xinjiang. Guarantee the Xinjiang economy and society to quickly catch up with the national average level through cadre and talent assistance for Xinjiang so as to provide conditions for the long-term development and prolonged political stability. Since 2010, the emphasis of Xinjiang reconstruction-assistance has been the improvement of people's livelihood, wining of public minds, gathering the will of people and ensuring the people of various nationalities in Xinjiang to enjoy the modern development achievements as well as launch of the related works under the objective of realization of synchronous construction of a moderately prosperous society for the whole Xinjiang with our country. The five-year Xinjiang reconstruction-assistance work has achieved remarkable achievements and great changes have taken place in the economic and social appearance of Xinjiang. However, issues also appear since implementation of Xinjiang reconstruction-assistance, such as intensified regional disparity, further expansion of income gap, simplification of investment, unbalanced regional development, etc. Also, the people in reconstructionassistance areas hold different attitudes and views toward the Xinjiang reconstruction-assistance due to the benefit distribution issues and difference between the expectation and reality of Xinjiang reconstruction-assistance.

It is considered in the literatures adopting satisfaction investigation as the main study method that the effects of a certain policy for residents can be measured through the satisfaction degree of residents. This thesis adopts this analytical thinking to determine the degrees of effects through the direct evaluations of residents on Xinjiang reconstruction-assistance ${ }^{1}$. This thesis firstly admits that the satisfaction evaluation of residents is an important method in the evaluation methods for effects of Xinjiang

\footnotetext{
${ }^{1}$ Of course, there is certain relatedness between the satisfaction degree of residents and the evaluation on effects of Xinjiang reconstructionassistance. But the subjective evaluation of residents is not all the factors that control the effects of Xinjiang reconstruction. Because of the difference of all the respondents, scopes and spatial and temporal distribution and the difference in contents involved in the questionnaire inquiry and questions set up, the obtained conclusions are different. It is found in this thesis that the early literatures also are involved with the factors on satisfaction degree evaluation, but those literatures just discuss the factors on satisfaction but have not put forward the basic facts behind the factors.
} 
reconstruction-assistance. But the thesis also emphasizes that the residents for effect evaluation must possess representativeness which can reflect the overall objective of Xinjiang reconstruction-assistance and considers that the basic reason for the occurrence of satisfaction difference is the key to formulate or adjust the policies, contents, measures and modes of Xinjiang reconstruction-assistance that are currently under implementation. When affirming the achievements of Xinjiang reconstruction-assistance in recent five years, the thesis takes the residents in three districts in south Xinjiang as the main objectives and will analyze the factors on satisfaction evaluation through the investigation on satisfaction degrees to further analyze the difference in satisfaction on the effects of Xinjiang reconstructionassistance so as to clarify the emphasis of Xinjiang reconstruction-assistance and put forward more effective policies for Xinjiang reconstruction-assistance as well as realize the great-leap-forward development and prolonged political stability of Xinjiang.

\section{LITERATURE REVIEW}

It is found in this thesis that most of the foreign studies on the construction-assistance are centralized on two aspects including the construction of assistance system of developed countries to the developing countries and the evaluation on implementation effects. Kim Richard Nossal (1998) systematically explained the motivation and objectives of the assistance of Canadian government; David Ellenman (2004) is the very first to put forward that the assistance of developed countries to developing countries must insist on the new assistance idea which takes self-dependence and enhancing of independent development as emphasis. Aiming at how can the less developed areas in south Italy get rid of the underdeveloped status and how to implement the assistance and other issues, Leopardi.Robert (1995) put forward the detailed assistance policies on aspects such as optimizing investment orientation of enterprises, improving the technology, expanding scale and implementing tax preference and other aspects and emphasized on the effectiveness of the cylinder system on this microcosmic level. While Ralph Lattimore (2003) discussed the effectiveness and referential modes of the industrial assistance policies implemented by the New Zealand Government on the underdeveloped areas and emphasized on the key role of industrial assistance on getting rid of the underdeveloped status. Martha Ann (2011) discussed the reasons of insufficient financial credit and put forward the innovative assistance measure such as issuing social bonds, etc by combining with the financial reality and financial repression state in underdeveloped areas.

The studies of domestic scholars on the foreign assistance are centered on the two aspects of theory summary and implementation effects. Cai Ling (2000) concentrated on study on the Germany regional assistance policies and thought after systematical combing that the legal construction of Germany assistance system possesses referential value for the Develop-the-West Strategy of our country and put forward the suggestions on legislation and administerization of assistance; Zhang Huizhi (2009) studied on the reality of assistance receiving in North Korea and its effects and thought that the key point of assistance in underdeveloped area shall be the infrastructure construction. The key point of industrial assistance shall be agriculture while the key point of effective government construction assistance shall be the improvement of administrative abilities, etc.

On the aspect of domestic regional assistance system construction, the domestic academia mainly conducts regional assistance studies from the perspectives of policy assistance system (Wei Houkai, 2004; Li Lulu \& Song Zhen, 2007), poverty alleviation (Lang Yongjian, Hu Jilian, 2004; Chen Zhigang, 2005), finance transfer and foreign investment (Shen Kunrong, etc, 2001, Wei Houkai, 2002) and transfer payment from the exchequer (Wu Wenzhong, 2010) and other perspectives. There are also part scholars conduct the regional assistance studies on the aspects of education (Kang Kai, 2004; Zheng Gang, 2012), legislation (Wang Yongcai, 2014) and post-disaster reconstruction (Liu Tie, 2010) and other aspects.

The high quality studies aiming at the counterpart Xinjiang reconstruction-assistance are not so many while the report or summative literatures are relatively abundant. It is found in this thesis after organizing the limited literature resources that the literatures about Xinjiang reconstructionassistance involve the counterpart Xinjiang reconstructionassistance of college (Liang Yong, 2009), legalization of Xinjiang reconstruction policies (Xiong Wenzhao, 2010), study on the relations between educational assistance of Xinjiang and economic growth (Chen Xia \& He Zhilun, 2010), the regional economic growth model of Xinjiang under the form of Xinjiang reconstruction-assistance (Duan $\mathrm{Li}, 2011$ ), study on the internal logic relations between counterpart Xinjiang reconstruction-assistance and construction of the economic development zones in underdeveloped areas (Meng Hui \& Li Ziye, 2012) etc.

Conducting studies from the evaluation on implementation of Xinjiang reconstruction-assistance has become a kind of tendency. Chen Xiaokun and others (2013) conducted the empirical analysis on the satisfaction of local residents in areas receiving assistance on the implementation of Xinjiang reconstruction-assistance and the satisfaction on the work of local government through the questionnaire survey in fifteen areas in Xinjiang [1]. Ma Rong put forward policy suggestions on the implementation of counterpart Xinjiang reconstruction-assistance policies through the field research in Kashi Prefecture, Akesu Prefecture and Hotan Prefecture [2]. Gu Suna (2014) conducted the empirical analysis on the implementation effects of new counterpart Xinjiang reconstruction-assistance policies through the questionnaire survey conducted in Hotan Prefecture in Xinjiang [3]. Gao Zhigang and others (2015) conducted analysis on the evaluation of the public towards the economic effects of counterpart Xinjiang reconstructionassistance policies and the performance abilities of local government through questionnaire survey conducted in Altay Prefecture in Xinjiang by adopting the method of character visiting [4]. Li Dashuang and others (2012) conducted empirical analysis on the satisfaction of implementation of 
counterpart Xinjiang reconstruction-assistance policies of residents through the questionnaire survey conducted in Yumin County in Xinjiang by adopting the methods of crosstab analysis and factor analysis [5].

From the above studies, the implementation of counterpart Xinjiang reconstruction-assistance is mainly concentrated on the perspectives of education, legal system, factors for economic growth, implementation effects and the satisfaction of residents to conduct studies. Most of the studies on implementation effects and satisfaction of Xinjiang reconstruction-assistance adopt the descriptive analysis and the analysis on factors of evaluation on satisfaction of residents on Xinjiang reconstructionassistance policies and the deep reasons behind is not thorough. This study takes the study on factors of satisfaction as the intermediate objective, takes explanation of the factors behind the factors of satisfaction as the final objective and uses ordinal logistic regression model to conduct empirical analysis on the factors of satisfaction of residents on the counterpart Xinjiang reconstruction-assistance. This study also deeply discusses the factors behind the factors of satisfaction and put forward corresponding policy suggestions based on the above.

\section{STUDY METHODS}

\section{A. Value Range}

To measure the satisfaction of residents on the implementation of Xinjiang reconstruction-assistance, the value range of the satisfaction of residents on the Xinjiang reconstruction-assistance shall be firstly defined. It is also controversial about the value range. Some scholars of the literatures collected in this thesis directly assume the value range for satisfaction of residents on the implementation of counterpart Xinjiang reconstruction-assistance to be tow levels of $[0,1]$ which are not satisfactory and satisfactory 2 . It is noticed in this thesis that most of scholars who study the issue of satisfaction would prefer relatively more levels as the value range with the hope of mastering the detailed mentality and factors of evaluators as far as possible [6]. It is also thought in this thesis that the levels of satisfaction of residents on the implementation of Xinjiang reconstructionassistance policy are too little which cannot reflect the details of evaluation on the implementation effects of Xinjiang reconstruction-assistance policy. However, if the levels are too many, it will make it difficult for investigators in grasping the difference thereinto. Therefore, the five-level system will be more suitable to be adopted. In this thesis, the satisfaction levels on the implementation of Xinjiang reconstruction-assistance policy are divided into levels from "1 to 5" which separately means "very satisfactory", "satisfactory", "ordinary". "unsatisfactory" and "very unsatisfactory". The evaluation values are obtained by adopting the measure of direct judgment on the satisfaction levels on the implementation of Xinjiang reconstructionassistance of the residents under investigation [7].

${ }^{2}$ Gu Suna (2014)

\section{B. Study Hypothesis}

The factors of satisfaction levels on the implementation of Xinjiang reconstruction-assistance of the residents originates from the factors based on individual factors, cognition and objective facts. The satisfaction level based on individual mainly dependents on the individual characters of residents. The satisfaction based on cognition is based on the understanding and the attitudes of Xinjiang reconstructionassistance policy of individuals. The satisfaction based on objective facts is based on the satisfaction level on the improvement of people's livelihood of residents [8].

About the factor of individual characters, it is assumed in thesis that the individual characters of residents such as gender, age, income, education, vocation, nation and region, etc will impact the evaluation on the satisfaction on implementation of Xinjiang reconstruction-assistance policy of residents.

About the factor of cognation, it is assumed in this thesis that the attitude on implementation of Xinjiang reconstruction-assistance polity of residents and comprehend of Xinjiang reconstruction-assistance policy, etc are the main factor variables for discussion of the impacts on evaluation of satisfaction level on implementation of Xinjiang reconstruction-assistance policy of the above characters of residents.

About the factor based on objective facts, it is considered in this thesis that the improvement of people's livelihood is the key point of this Xinjiang reconstruction policy. Taking the improvement of people's livelihood as the investigation contents of satisfaction, the residents will be more inclined to provide true thoughts. Therefore, this thesis assumes the variables on the improvement of people's livelihood such as satisfaction level on infrastructure improvement (IC-Imp), satisfaction level on the education improvement (Edu-Imp), satisfaction level on the health care improvement (He-Imp), satisfaction level on the income improvement (In-Imp), satisfaction level on the housing improvement (Ho-Imp) and satisfaction level on the basic service improvement (BS-Imp), etc of residents and discusses how to evaluate the satisfaction level on the Xinjiang reconstruction-assistance policy of residents.

\section{Construction of Model}

The evaluation which can reflect the satisfaction on implementation effects of Xinjiang reconstruction-assistance of residents is the discrete data which is mainly ordinal categorical data. When studying the issue of discrete selection models, using the probability model is a good evaluation method. Generally speaking, the probability models are divided into binary selection model and multipleselection model. There is no limitation on the class number of explained variables in the multiple-selection model. When the discrete value of explained variables is more than two, the multiple-probability model must be adopted [9]. Because the explained variables analyzed in this thesis are too many and there is strong ordered relation among each value, the ordinal logistic regression model shall be further adopted to analyze the factors of satisfaction level on implementation 
effects evaluation of Xinjiang reconstruction-assistance policy of residents.

The explained variable CPRS is set in the thesis which is divided into five-level ordinal variables,

$$
\begin{aligned}
& C P R S_{i}=1,2, \cdots, 5 ; \quad X_{i}^{\prime}=\left(X_{i 1}, X_{i 2}, \cdots \cdots \cdots, X_{i k}\right) \text { are the } \\
& \quad p=\left(C P R S_{i} \geq K \mid X_{i}\right)=P\left(C P R S_{i}=K \mid X_{i}\right)+P(C P \\
& =p_{k}+p_{k+1}+p_{5}
\end{aligned}
$$$$
p=\left(C P R S_{i} \geq K \mid X_{i}\right)=P\left(C P R S_{i}=K \mid X_{i}\right)+P\left(C P R S_{i}=K+1 \mid X_{i}\right)+P\left(C P R S_{i}=5 \mid X_{i}\right)
$$

explanatory variables ; note the probability of level $\mathrm{K}$ of $\mathrm{CPRS}_{i} \quad$ as $\quad P\left(C P R S_{i}=K \mid X_{i}\right)=P_{K}$ where $K=1,2, \cdots, 5$. Therefore, the probability with level of $C P R S_{i}$ being equal to or more than $\mathrm{K}$ is:

Take the $P\left(C P R S_{i} \geq K \mid X_{i}\right)$ as the cumulative probability of being equal or more than K. Alter the $P\left(C P R S_{i} \geq K \mid X X_{i}\right)$, $\log$ istic $\left._{P} P\left(C P R S_{i} \geq K \mid X_{i}\right)\right]=\ln \frac{P\left(C P R S_{i} \geq K \mid X_{i}\right)}{1-P\left(C P R S_{i} \geq K \mid X_{i}\right)}=\alpha_{k}+\sum_{i=1}^{n} \beta_{i} X_{i}(k=1,2, \cdots, 5 ; i=1,2, \cdots, n)$

Through equivalent transformation, the formula (2) can be transferred into formula (3).

$$
P\left(C P R S_{i} \geq K \mid X_{i}\right)=\frac{\exp \left(\alpha_{k}+\sum_{i=1}^{n} \beta_{i} X_{i}\right)}{1+\exp \left(\alpha_{k}+\sum_{i=1}^{n} \beta_{i} X_{i}\right)}
$$

According to the study objectives of this thesis, the explained variable CPRS represents the satisfaction level on the implementation effects of Xinjiang reconstructionassistance policy of residents. The explanatory variable $X_{i}^{\prime}=\left(X_{i 1}, X_{i 2}, \cdots \cdots \cdots, X_{i k}\right)$ is the factor representing the impacts on the satisfaction level on implementation effects of Xinjiang reconstruction-assistance policy of residents. $\alpha_{i}$ and $\beta_{i}$ are the parameters for evaluation. $\alpha_{i}$ is the intercept parameter and $\beta_{i}$ is the regression coefficient [10].

\section{EMPIRICAL ANALYSIS}

\section{A. Descriptive Statistics of Sample}

The quota sampling method is adopted in this thesis to conduct questionnaire survey to the residents in three districts in south Xinjiang. The investigation contents involve the individual characters of residents, the actual implementation conditions of Xinjiang reconstructionassistance policy and the improvement of people's livelihood. Total 1800 copies of questionnaires are provided in this field investigation and 1728 copies have been returned with the return rate of $94 \%$. Thereinto, the quantity of valid questionnaires is 1498 copies with the valid rate of $86.68 \%$. Among the samples under investigation, males account for $55.6 \%$ and females account for $44.6 \%$; people with educational level of middle or primary schools account for 29.7, people with educational level of junior high school account for $31 \%$, people with educational level of senior high school account for $31.3 \%$, people with educational level of junior college, technical secondary school and vocational school account for $4.9 \%$ and people with educational level of bachelor degree or above account for $3.3 \%$; in the layout of income, people with annual household income of below
$5000 y u a n$ account for $16.7 \%$, people with annual household income between 5000 and 10000yuan account for $21.8 \%$, people with annual household income of between 10000 and 20000 yaun account for $40.3 \%$, people with annual household income of between 20000 and 30000yuan account for $8.6 \%$, people with annual household income of between 30000 and 50000 yaun account for $6.6 \%$, people with annual household income of between 50000 and 80000yuan account for $5.4 \%$ and people with annual household income of between 80000 and 100000yuan account for $0.7 \%$; in the layout of vocational structure, students account for $11.9 \%$, teachers account for $6.8 \%$, employees of state-owned enterprise account for $5.9 \%$, employees of the private enterprises account for $2.6 \%$, agro-pastoralists account for $56.3 \%$, selfemployed businessmen account for $6.5 \%$, soldiers accounts for $0.93 \%$, cadres accounts for $0.8 \%$, medical staff accounts for $1.1 \%$, people in service industry account for $0.5 \%$, rolling stones account for $3.2 \%$ and people with other vocations account for $3.5 \%$; in the layout of national structure, uygur accounts for $56.2 \%$, the Han nationality accounts for $26.1 \%$ and other nationalities account for $17.7 \%$. We can see from the above data that among the samples under investigation, males are more than females, the proportion of people with educational level of senior high school and junior high school is higher with the relatively low income of between 5000 and 20000 which can comply with the basic characters of resident group in south Xinjiang.

\section{B. Setting and Selection of Variables}

This thesis emphasizes on the analysis on the factors of satisfaction level on the implementation effects of Xinjiang reconstruction-assistance policy of residents. Therefore, the satisfaction level on implementation effects of Xinjiang reconstruction-assistance shall be adopted as the explained variable and the analyzed three major kinds of factors above shall be divided into 19 seed factors as the explanatory variables to conduct the statistical regression analysis on that. 
See "Table I" for the setting of variables and the related data description obtained from investigation.

TABLE I. SETTING AND DESCRIPTION OF VARIABLES

\begin{tabular}{|c|c|c|}
\hline $\begin{array}{l}\text { Name of } \\
\text { variable }\end{array}$ & $\begin{array}{l}\text { Meaning of } \\
\text { variable }\end{array}$ & Value and definition of variable \\
\hline \multicolumn{3}{|c|}{ Dependent variable } \\
\hline CPRS & $\begin{array}{l}\text { Satisfaction level } \\
\text { on Xinjiang } \\
\text { reconstruction- } \\
\text { assistance policy } \\
\text { of residents }\end{array}$ & $\begin{array}{l}5=\text { very satisfactory, } 4=\text { satisfactory, } \\
3=\text { ordinary, } 2=\text { unsatisfactory, } 1= \\
\text { very unsatisfactory }\end{array}$ \\
\hline \multicolumn{3}{|c|}{ Independent variable } \\
\hline Gender & $\begin{array}{l}\text { Gender, dummy } \\
\text { variable }\end{array}$ & $1=$ male, $0=$ female \\
\hline Age & Age & $\begin{array}{l}1=\text { below } 20,2=20 \text { to } 30,3=30 \text { to } \\
40,4=40 \text { to } 50,5=\text { over } 50\end{array}$ \\
\hline Income & Income & $\begin{array}{l}1=\text { below } 10000,2=10001 \text { to } 20000, \\
3=20001 \text { to } 30000,4=\text { over } 30001\end{array}$ \\
\hline Education & Educational level & $\begin{array}{l}1=\text { primary school or below, } 2= \\
\text { junior high school, } 3=\text { high school, } \\
4=\text { junior college, technical secondary } \\
\text { school and technical school, } 5= \\
\text { bachelor degree and above }\end{array}$ \\
\hline vocation1 & $\begin{array}{l}\text { Vocation, dummy } \\
\text { variable }\end{array}$ & $\begin{array}{l}1=\text { agro-pastoralists, } 0=\text { other } \\
\text { vocations }\end{array}$ \\
\hline vocation 2 & $\begin{array}{l}\text { Vocation, dummy } \\
\text { variable }\end{array}$ & $\begin{array}{l}1=\text { public institution and civil } \\
\text { servants, } 0=\text { other vocations }\end{array}$ \\
\hline vocation3 & $\begin{array}{l}\text { Vocation, dummy } \\
\text { variable }\end{array}$ & $\begin{array}{l}1=\text { employees in private enterprises, } \\
0=\text { other vocations }\end{array}$ \\
\hline Nation1 & $\begin{array}{l}\text { Nationality, } \\
\text { dummy variable }\end{array}$ & $\begin{array}{l}1=\text { Uyghur nationality, } 0=\text { other } \\
\text { nationalities }\end{array}$ \\
\hline Nation2 & $\begin{array}{l}\text { Nationality, } \\
\text { dummy variable }\end{array}$ & $\begin{array}{l}1=\text { the Han nationality, } 0=\text { other } \\
\text { nationalities }\end{array}$ \\
\hline Region1 & $\begin{array}{l}\text { Region, dummy } \\
\text { variable }\end{array}$ & $1=$ Kashgar, $0=$ other regions \\
\hline Region1 & $\begin{array}{l}\text { Region, dummy } \\
\text { variable }\end{array}$ & $1=$ Khotan, $0=$ other regions \\
\hline $\begin{array}{l}\text { Comprehen } \\
\text { d }\end{array}$ & $\begin{array}{l}\text { Understand } \\
\text { Xinjiang } \\
\text { reconstruction- } \\
\text { assistance policy } \\
\text { or not }\end{array}$ & $1=$ yes, $2=$ no \\
\hline Attitude & $\begin{array}{l}\text { Attitudes toward } \\
\text { Xinjiang } \\
\text { reconstruction- } \\
\text { assistance policy }\end{array}$ & $\begin{array}{l}5=\text { very trust, } 4=\text { trust, } 3=\text { ordinary, } \\
2=\text { not trust, } 1=\text { very not trust }\end{array}$ \\
\hline IC-Imp & $\begin{array}{l}\text { Improvement of } \\
\text { infrastructure }\end{array}$ & $\begin{array}{l}5=\text { very satisfactory, } 4=\text { satisfactory, } \\
3=\text { ordinary, } 2=\text { unsatisfactory, } 1= \\
\text { very unsatisfactory }\end{array}$ \\
\hline Edu-Imp & $\begin{array}{l}\text { Improvement of } \\
\text { education }\end{array}$ & $\begin{array}{l}5=\text { very satisfactory, } 4=\text { satisfactory, } \\
3=\text { ordinary, } 2=\text { unsatisfactory, } 1= \\
\text { very unsatisfactory }\end{array}$ \\
\hline He-Imp & $\begin{array}{l}\text { Improvement of } \\
\text { health care }\end{array}$ & $\begin{array}{l}5=\text { very satisfactory, } 4=\text { satisfactory, } \\
3=\text { ordinary, } 2=\text { unsatisfactory, } 1= \\
\text { very unsatisfactory }\end{array}$ \\
\hline In-Imp & $\begin{array}{l}\text { Improvement of } \\
\text { income }\end{array}$ & $\begin{array}{l}5=\text { very satisfactory, } 4=\text { satisfactory, } \\
3=\text { ordinary, } 2=\text { unsatisfactory, } 1= \\
\text { very unsatisfactory }\end{array}$ \\
\hline Ho-Imp & $\begin{array}{l}\text { Improvement of } \\
\text { housing }\end{array}$ & $\begin{array}{l}5=\text { very satisfactory, } 4=\text { satisfactory, } \\
3=\text { ordinary, } 2=\text { unsatisfactory, } 1= \\
\text { very unsatisfactory }\end{array}$ \\
\hline BS-Imp & $\begin{array}{l}\text { Improvement of } \\
\text { basic service }\end{array}$ & $\begin{array}{l}5=\text { very satisfactory, } 4=\text { satisfactory, } \\
3=\text { ordinary, } 2=\text { unsatisfactory, } 1= \\
\text { very unsatisfactory }\end{array}$ \\
\hline
\end{tabular}

\section{Estimation of Model Parameter and Analysis on Results}

Based on the above established variable system and value range, this thesis conducts the multiple ordinal logistic regression analysis on that. The results of regression analysis are as shown in "Table II".

TABLE II. ESTIMATION RESUlTS OF LOGISTIC REGRESSION MODEL PARAMETERS

\begin{tabular}{|c|c|c|c|c|}
\hline Variable & Coefficient & $\begin{array}{l}\text { Standard } \\
\text { deviation }\end{array}$ & $\mathbf{Z}$ statistics & $P$ value \\
\hline GENDER & -0.309119 & 0.296186 & -1.043664 & 0.2966 \\
\hline AGE & 0.311600 & 0.149663 & 2.082007 & 0.0373 \\
\hline INCOME & 0.610970 & 0.195154 & 3.130705 & 0.0017 \\
\hline EDUCATION & 0.299526 & 0.154652 & 1.936777 & 0.0528 \\
\hline VOCATION1 & -0.365408 & 0.383344 & -0.953211 & 0.3405 \\
\hline VOCATION2 & 1.658535 & 0.227077 & 7.303841 & 0.0000 \\
\hline VOCATION3 & -1.387268 & 0.517704 & -2.679656 & 0.0074 \\
\hline NATION1 & -0.170551 & 0.398193 & -0.428313 & 0.6684 \\
\hline NATION2 & -0.428636 & 0.429422 & -0.998169 & 0.3182 \\
\hline REGION1 & 0.144962 & 0.377788 & 0.383714 & 0.7012 \\
\hline REGION2 & 0.071892 & 0.381019 & 0.188685 & 0.8503 \\
\hline COMPREHEND & 0.819662 & 0.371181 & 2.208254 & 0.0272 \\
\hline ATTITUDE & 0.452764 & 0.073248 & 6.181247 & 0.0000 \\
\hline IC-Imp & 2.918855 & 0.278349 & 10.48630 & 0.0000 \\
\hline Edu-Imp & 3.392745 & 0.323830 & 10.47692 & 0.0000 \\
\hline He-Imp & 2.804677 & 0.312678 & 8.969858 & 0.0000 \\
\hline In-Imp & 4.066258 & 0.390260 & 10.41935 & 0.0000 \\
\hline Ho-Imp & 3.024436 & 0.303184 & 9.975583 & 0.0000 \\
\hline BS-Imp & 2.880892 & 0.314301 & 9.166041 & 0.0000 \\
\hline Overall inspection & statistics of & model & & \\
\hline Pseudo R-squared & 0.838526 & \multicolumn{2}{|c|}{ Akaike info criterion } & 0.328020 \\
\hline Schwarz criterion & 0.407187 & \multicolumn{2}{|c|}{ Log likelihood } & -206.8099 \\
\hline $\begin{array}{l}\text { Hannan-Quinn } \\
\text { criter. }\end{array}$ & 0.357626 & \multicolumn{2}{|c|}{ Restr. log likelihood } & -1280.759 \\
\hline LR statistic & 2147.899 & \multicolumn{2}{|c|}{ Avg. log likelihood } & -0.148891 \\
\hline Prob(LR statistic) & 0.000000 & & & \\
\hline
\end{tabular}

It is indicated in the estimation results of regression model parameter that there in no significant difference of age, educational level, urban residents and employees in public institution, income level and other resident characters showing in the satisfaction level on attitude toward Xinjiang reconstruction-assistance policy, transparency of polity, infrastructure, health care level, education improvement, income increasing, housing conditions, basic service effects and other detailed effects of Xinjiang reconstructionassistance policy. Viewing from such characters, significant fairness and sharing characters are shown in the effects of Xinjiang reconstruction-assistance. However, taking the employees in private enterprises as the resident character, the factor possesses significant negative effects on the satisfaction level on the implementation effects of Xinjiang reconstruction-assistance policy and there exists the feeling of not being recognized or no sense of gain. There is no significant difference on the satisfaction level on 
implementation effects of Xinjiang reconstruction-assistance policy of space layout, nationality characters and other resident character factors. However, viewing from the overall inspection statistics, there are significant differences in the impacts on different satisfaction level indicators of each factor.

Firstly, age, resident income level and the educational level and other resident characters have significant positive impacts on the evaluation of satisfaction level on the implementation effects of Xinjiang reconstruction-assistance policy with the coefficient of 0.3116 and the level of significance of 0.0017 . And the older is the residents, the higher is the satisfaction level on the implementation effects of Xinjiang reconstruction-assistance policy. The educational level of residents has significant positive impact on the evaluation of satisfaction level on the implementation effects of Xinjiang reconstruction-assistance policy with the coefficient of 0.299526and the level of significance of 0.0528. And the higher is the educational level of residents, the higher is the satisfaction level on the implementation effects of Xinjiang reconstruction-assistance policy.

Secondly, a distinct contrast is formed between the distinct of public business and the identity characteristics of agro-pastoralists and private enterprises. The employees in public business units and civil servants have significant positive impacts on the implementation effects of Xinjiang reconstruction-assistance policy with the coefficient of 1.658535 and the significance level of 0.0000 which means that the employees in public business units and civil servants are very satisfactory with the implementation effects of Xinjiang reconstruction-assistance policy compared with people in other vocations. The impacts of the identity character of agro-pastoralists on the evaluation of satisfaction level on implementation effects of Xinjiang reconstruction-assistance policy are not significant but possess the tendency of negative relevance, because the impact coefficient is -0.365408 and the level of significance is 0.3405 which means that the satisfaction level on implementation effects of Xinjiang reconstruction-assistance policy is not that significant compared with that of other vocations. On the contrary, it tends to be unsatisfactory. The employees in private enterprises possess significant negative impacts on the satisfaction level on the implementation effects of Xinjiang reconstruction-assistance policy with the coefficient of -1.387268 and the level of significance of 0.0074 which means that the employees in private enterprises are unsatisfactory with the implementation effects of Xinjiang reconstruction-assistance policy compared with people with other vocations.

Thirdly, there is positive impact between the attitude and comprehend level on Xinjiang reconstruction-assistance policy of resident and the evaluation of satisfaction level on implementation effects of Xinjiang reconstruction-assistance policy. The impacts on the evaluation of satisfaction level of the attitude of residents toward Xinjiang reconstructionassistance policy is significantly positive with the coefficient of 0.819662 and the level of significance of 0.0272 which means that the stronger is the credibility on Xinjiang reconstruction-assistance policy of residents, the higher is the satisfaction level on the implementation effects of Xinjiang reconstruction-assistance policy. This indicates that the higher the comprehend level and awareness level of the policy are, the higher the evaluation value of satisfaction level on the effects of Xinjiang reconstruction-assistance policy.

Fourth, the improvement of people's livelihood has positive impacts on the evaluation of satisfaction level on the effects of Xinjiang reconstruction-assistance. However, there is difference on the satisfaction level of Xinjiang reconstruction-assistance of different livelihood projects. The coefficient for satisfaction level on this Xinjiang reconstruction-assistance effect of the improvement on income of people is the highest (4.066258). The coefficient for satisfaction level of improvement on educational level is the second (3.392745). The third is the coefficient for satisfaction level of improvement of housing (3.024436). The fourth is the coefficient for satisfaction level of the improvement of infrastructure (2.918855). The fifth is the coefficient for satisfaction level of improvement on basic service (2.880892) and the final is the coefficient for satisfaction level of improvement on health care level (2.804677). The levels of significance of all above coefficients are 0.0000 which means that there are differences in the effects in specific practice of the livelihood projects effects driven by the Xinjiang reconstructionassistance.

\section{ANALYSIS ON THE RESUlts AND POLICY SUGGESTIONS}

\section{A. Analysis on Results}

Why are there the above results? A simple reason analysis is conducted in this thesis.

Firstly, the economic and social structures in three districts in south Xinjiang cause that there is no difference in the evaluation of satisfaction level on the Xinjiang reconstruction-assistance effects of the resident characters such as gender, ethnic group and space layout, etc. on one hand, the regions under investigation are all in the three districts in south Xinjiang which are the concentration area of national-level poverty-stricken counties and has been receiving certain policy support as the nationally independently focused regions since 2007. Therefore, it is impossible to produce differences on the aspect of satisfaction level on the Xinjiang reconstruction-assistance effects in the space layout characters. Secondly, there is no difference in ethnic group indicating that the regional equity emphasized in the Xinjiang reconstruction-assistance policy is much better that the traditional policies on the nationality equity. The regional characters are emphasized in the implementation of policy but the difference in ethnic group is not emphasized3. Thirdly, the reason why the difference in

\footnotetext{
3 It is also considered in this thesis whether the population under investigation is concentrated in a certain nationality. It is found in the ethnic group layout of questionnaire that only about $73 \%$ of people under investigation are local national minorities which covers more the Han nationality group and other ethnic groups based on the basic fact that the ratio of local national minorities exceeds $90 \%$. Therefore, it is thought in
} 
gender has not become the factor for evaluation of difference is that the differences in male and female decisions in three districts in south Xinjiang are much less. And most of them enjoy the same treatment in social and economic rights and there are no main disturbing effects produced due to gender ratio.

Secondly, the differences in cognation are the key to cause the differences in satisfaction level. There are only two kinds of factors of cognition in this thesis, one being comprehend level, the other being the attitudes toward this policy. It is shown in the study results that the deeper the cognition level is, the better the impacts on evaluation of satisfaction level will be and the higher the evaluation value will be. The higher the credibility on this policy is, the higher the evaluation value will be and the higher the satisfaction level will be. This explains that when evaluating the effects of Xinjiang reconstruction-assistance, if the questionnaire survey adopts the masses with high cognition and credibility on policy as the object to obtain the results, it will be inconsistent with the results obtained by adopting the population of other levels as the object. The cognition difference of different identities and income groups are the levels of the impacts on the difference in evaluation of satisfaction level of the individual characters featured with differences in ages, vocations and income. On one hand, it is found in this thesis that the impacts of age difference are relatively significant. The young people hold the skepticism or low evaluation value toward the Xinjiang reconstructionassistance policy. While the older the ages are, the higher the evaluation of this polity will be. This is mainly because of the differences in cognition and recognition caused by the comparison between the past and current of people with higher ages. However, the young people become the disadvantaged group in the Xinjiang reconstructionassistance and the direct experiencers of pressure of competition. Secondly, the identity of agro-pastoralists has no difference in the evaluation of satisfaction levels on Xinjiang reconstruction-assistance policy which means that the agro-pastoralists know very little about the Xinjiang reconstruction-assistance policy and are interested in the detailed changes produced but are not interested in the implementation of policy and theoretical issues behind the detailed changes. The identities of civil servants and employees in public institutions deeply understand the Xinjiang reconstruction-assistance policy and are the main implementation groups and executors of the policy. Thirdly, the Xinjiang reconstruction-assistance policy has different actual impacts on groups with different incomes. Therefore, the higher the income is, the greater the impacts on the evaluation will be. Normally, the groups with low income are the direct beneficiaries of Xinjiang reconstructionassistance policy. However, it is found in this theory that the impacts on evaluation of satisfaction level of groups with low income are negative and the higher the income is, the higher the evaluation will be. This causes that after the implementation of Xinjiang reconstruction-assistance policy, the benefits gained by the group with higher income are

this thesis that the relatively fair and objective results come along with the region-oriented policies. much more that that gained by the group with lower income. Fourthly, the impacts on evaluation of satisfaction level on Xinjiang reconstruction-assistance policy of the employees in private enterprises are negative. This is mainly because of the competitive pressure, employment pressure and extrusion pressure caused by the economy under closed state meeting the opening environment. Therefore, the employees in private enterprises hold certain skepticism to the effects of Xinjiang reconstruction-assistance policy which exerts negative impacts on the evaluation of satisfaction level.

Thirdly, the factor of objective faces has higher impacts on the evaluation of satisfaction level. It is shown in the results of this study that the impacts on evaluation of satisfaction level on Xinjiang reconstruction-assistance policy of the satisfaction level on the aspects of improvement of housing, education, income, health care, infrastructure and basic service and other objective facts are all positive. Thereinto, the evaluation of satisfaction level on improvement of income has the greatest impacts on the evaluation of overall evaluation of satisfaction level. While the evaluation of satisfaction level on improvement of basic service and health care has the lowest impacts on the evaluation of overall evaluation of satisfaction level. On one hand, this result shows that the Xinjiang reconstructionassistance has received high recognition of residents in the three districts in south Xinjiang on the fields of income increasing, optimization of education conditions, improvement of housing environment and construction of infrastructure, etc. However, the aspects of improvement of basic service and health care conditions have not received high recognition. The reason why is that the improvement of income can be easily felt through the system of lowest living ensure and various subsidies and allowance. The hosing environment improvement is realized through the central, local and individual rising measures which reduces the burdens on housing of residents and will be easily evaluated. Because of the reconstruction and new construction of schools and the more and more optimized teaching staff, the education condition can provide more school subsidies and student subsidizes which has played its role. The improvement of infrastructure is mainly manifested in the energization, road and running water and other livelihood projects. Actually, the investment on above fields is large indeed and the improvement scope in recent five years is also large. However, the improvement of infrastructure with largest investment is in the final place which induces the doubts of residents. The possible explanation is that although issue of hardware basis of health care center can be solved in short term, the improvement of medical skill level put into by the personnel for health care need the long-term training. Therefore, it will be difficult in being recognized by the residents. In this factor, the fact that satisfaction level coefficient on improvement of basic service is lower indicates that the service awareness of base shall be further emphasized in the future work.

\section{B. Policy Suggestions}

Firstly, complete the explanation and propaganda work of targeted Xinjiang reconstruction-assistance policy aiming 
at groups with different cognition levels. The foregoing analysis conclusions indicate that the difference in cognition is the key of the difference in satisfaction level on Xinjiang reconstruction-assistance policy. And the main individual character factors which cause the difference in cognition are the vocation identity, nature of employment unit and educational level. Therefore, on one hand, aim at the agropastoralists to enhance the propaganda work of Xinjiang reconstruction-assistance policy because the proportion of agro-pastoralists in Xinjiang is large where the national minorities account for about $75 \%$. If the main group of agropastoralists of national minorities cannot comprehend the Xinjiang reconstruction-assistance policy and has low satisfaction level or negative impacts towards the Xinjiang reconstruction-assistance effects due to the issue of cognition, it will exert negative impacts on the stability and prolonged political stability of Xinjiang. Secondly, the publicity and education aiming at young labors are very important. It is found in this thesis that from the perspective of gender difference, the evaluation value of young group teammates on the policy is not high or even is negative. This group should know better about the opportunities brought for them by the Xinjiang reconstruction-assistance policy and the policy will teach them about how to respond to the challenges brought by the changes. Especially, the skill training and entrepreneurship support shall be enhanced and the transfer employment abilty shall be quickly improved. More capital and policy support in the Xinjiang reconstruction-assistance policy are more inclined to the solution to the specific demands of such people.

Secondly, practically change the measures and methods of basic work, improve the service environment and quality and increase the policy transparency. It is found in this thesis that in the specific evaluation of Xinjiang reconstructionassistance effects, the evaluation of quality of basic service is the lowest. Therefore, the further Xinjiang reconstructionassistance policy should enhance the service awareness of local government, especially of the basic service awareness and improve the transparency of Xinjiang reconstructionassistance policy. It is thought in this thesis that on one hand, the construction of self-ability of grass-roots cadres and masses is very important. They should not only learn to grasp the stability but also should learn to focus on the economy. Both aspects should be focused on and both aspect will be enhanced. Learn to focus on both aspects. Take one aspect as the support point of stability while take another aspect as the support point of economic spanning. Secondly, the work measure and method have been innovated. There should be innovative thoughts in the work. They should learn to handle detailed matters through corresponding methods, dare to bear their responsibilities, not to pass the buck to the superior or the policy of "waiting, relying and asking" and dare to innovate and bear responsibilities. Thirdly, the quality of small part of grass-roots minority nationality cadres shall be further improved. Because the national minority masses are the main service object, the grass-roots cadres shall not only be the executors of policy, but importantly is the interpreters and transmitter of policy. Especially, when meeting the conflict issues due to cultural values, they should pay attention to the work measures and methods, should explain and interpret with innovation and should implement related work.

Thirdly, pay close attention to industries impacted by the Xinjiang reconstruction-assistance policy, especially the rebalance of benefits of masses impacted by the competition in the opening environment with their benefits being damaged. Create mire employment and living space. It is found in this thesis that the young farmer and employees in private enterprises hold doubts in the implementation effects of Xinjiang reconstruction-assistance policy or even hold the negative evaluation attitude. This is because large quantity of industrial capital swarms into under the opening environment which extrudes the original small-scale private enterprises from the living space. The small capital is extruded by large capital and the small-scale enterprises are extruded out by the large-scale enterprises. The work posts of modern largescale enterprises cannot produce the driving force of employment for the employees in small-scale enterprises. For this reason, firstly, in the Xinjiang reconstructionassistance, not only the entering of large-scale enterprises into Xinjiang shall be focused on, but the living space of original enterprises shall also be taken into consideration. Cultivate the enterprises on how to cultivate the ability to cultivate the living space in the industrial chain of large-scale enterprises and groups. Secondly, provide living space for the small-scale capital. The large-scale capital is actually the outcome of concentration of capital. The original small-scale capital in Xinjiang has played great functions in the original development. Due to the swarming into of large-scale capital, the situation where the small-scale capital cannot find the suitable financing platform and cannot live also appears. Therefore, how to motivate the market for small-scale capital in Xinjiang, how to drive the market for small-scale market to develop into the policy center together in the Xinjiang reconstruction-assistance policy? Thirdly, the middle and small-scale enterprises that indeed belong to invalid productivity and outdated productivity shall be conducted with reorganization and the retraining and re-employment of laid-off employees in private enterprises in the above enterprises shall be speeded up.

Fourthly, pay more attention to ensure the young generation to benefit from the Xinjiang reconstructionassistance policy. It is found in this thesis that the teammates of young generation possess certain antipathy of the policy. The teammates possess misunderstanding in the current employment situation, improvement of income and improvement in living conditions, etc after implementation of policy. They also have low credibility to the policy. Therefore, how to ensure the young generation to obtain more employment opportunities, more self-expression platform and more entrepreneurial opportunities in the Xinjiang reconstruction-assistance policy so as to improve the credibility to the Xinjiang reconstruction-assistance policy effects of young generation are also the important work for economic growth and social stability of Xinjiang. 


\section{REFERENCES}

[1] Chen Xiaokun, Tang Wuying. Analysis on the Satisfaction Level And Implementation Effects of Counterpart Xinjiang ReconstructionAssistance Policy- Based on the Investigation Data of 15 Districts[J]. Xinjiang University of Finance and Economics, May 2013: 74-80.

[2] Ma Rong. Investigation and Analysis on the Implementation Conditions of Counterpart Xinjiang Reconstruction-Assistance Project [J]. Journal of Minzu University of China (Philosophy and Social Sciences Edition), January 2014: 5-15.

[3] Gu Suna. Evaluation of Implementation Performance of Counterpart Xinjiang Reconstruction-Assistance Policy of China Based on the Satisfaction Level of Residents- A Case Study of Khotan City[J]. Xinjiang State Farms Economy, March 2014: 57-60.

[4] Gao Zhigang, Liu Wei \& Han Yanling. Analysis on the Economic Effects of Counterpart Xinjiang Reconstruction-Assistance and Promotion Strategy Based on the Questionnaire Survey - A Case Study of Altay Prefecture in Xinjiang[J]. Social Sciences in Xinjiang, April 2015: 125-131+164.

[5] Li Dashuang, Deng Yan, Wang Hao, Liang Jinming, Chen Jiangkang \& Chen Xiaokun. Investigation on the Satisfaction Level on Xinjiang Reconstruction-Assistance Work of Xinjiang Residents- Based on the Investigation Data of Yumin County[J]. Journal of Xinjiang University of Finance and Economics, March 2012: 74-80.

[6] Wang Hua, Jin Yongjin. Statistics Data Quality and User Satisfaction Level: Design of Performance Appraisal Sheet and Study on Practice[J]. Statistical Research. 2017(7)

[7] Yin Shijiu, Chen Mo, Xu Yingjun \& Li Zhongqiao. Credibility Evaluation and the Impact Factors for Food with Safety CertificateEmpirical Analysis Based on Ordinal Logistic Model[J]. Journal of Public Management, March 2013: 110-118+142.

[8] Li Jian, Huang Lei \& Yang Chengli. Analysis on the Factors for Quitting Wiling of Members in Farmer Specialized Cooperative Economy Organization Based on the Logistic Model- A Case Study of Jiangxi Province[J]. Journal of Agrotechnical Economics, July 2012: 111-118.

[9] Zhu Qianyu, Si Qingyang \& Zhou Zhen. Study on the Voluntary Transfer Willing of Rural Population Based on the Ordinal Logistic Model- Empirical Analysis on the Ecological Protective Screen Area in the Three Gorges[J]. Economic Theory and Business Management, November 2012: 104-112.

[10] Hao Jinlei, Jia Jinrong. Analysis on Factors of Willing for Selection of Endowment Patterns of Farmers in Western Region- Empirical Study Based on the Ordinal Probit Model and Structural Equation Model[J]. Statistics \& Information Forum, November 2010: 107-112. 